OPEN ACCESS

Edited by:

Sylvia Anton,

Institut National de la Recherche

Agronomique (INRA), France

Reviewed by:

Wolfgang Blenau,

Leipzig University, Germany

Cedric Neveu,

INRAE Val de Loire, France

*Correspondence:

Steeve H. Thany

steeve.thany@univ-orleans.fr

Specialty section:

This article was submitted to Invertebrate Physiology, a section of the journal

Frontiers in Physiology

Received: 23 August 2019

Accepted: 07 April 2020

Published: 07 May 2020

Citation:

Cartereau A, Taillebois $E$

Selvam B, Martin C, Graton J, Le Questel J-Y and Thany SH (2020) Cloning and Expression of Cockroach a7 Nicotinic Acetylcholine Receptor Subunit. Front. Physiol. 11:418. doi: 10.3389/fphys.2020.00418

\section{Cloning and Expression of Cockroach $\alpha 7$ Nicotinic Acetylcholine Receptor Subunit}

\author{
Alison Cartereau', Emiliane Taillebois' ${ }^{1}$ Balaji Selvam², Carine Martin ${ }^{1}$, Jérôme Graton ${ }^{3}$, \\ Jean-Yves Le Questel ${ }^{3}$ and Steeve H. Thany ${ }^{1 *}$ \\ ${ }^{1}$ LBLGC, UPRES EA 1207-USC INRA 1328, Université d'Orléans, Orléans, France, ${ }^{2}$ Roger Adams Laboratory, University \\ of Illinois at Urbana-Champaign, Urbana, IL, United States, ${ }^{3}$ CEISAM-UMR CNRS 6230, Faculté des Sciences et des \\ Techniques, Université de Nantes, Nantes, France
}

Understanding insect nicotinic acetylcholine receptor (nAChR) subtypes is of major interest because they are the main target of several insecticides. In this study, we have cloned a cockroach Pame 7 subunit that encodes a 518 amino acid protein with futures typical of nAChR subunit, and sequence homology to $\alpha 7$ subunit. Pame $\alpha 7$ is differently expressed in the cockroach nervous system, in particular in the antennal lobes, optical lobes and the mushroom bodies where specific expression was found in the non-compact Kenyon cells. In addition, we found that cockroach Pame 7 subunits expressed in Xenopus laevis oocytes can assemble to form homomeric receptors. Electrophysiological recordings using the two-electrode voltage clamp method demonstrated that nicotine induced an $I_{\max }$ current of $-92 \pm 27 \mathrm{nA}$ at $1 \mathrm{mM}$. Despite that currents are low with the endogenous ligand, ACh, this study provides information on the first expression of cockroach $\alpha 7$ homomeric receptor.

Keywords: nicotinic receptor, insect, $\alpha 7$ subunit, acetylcholine, nicotine, neonicotinoid

\section{INTRODUCTION}

Insect neuronal nicotinic acetylcholine receptors (nAChRs) are of particular interest because they are the main target of neonicotinoid insecticides, which are important in agriculture and veterinary medicine for controlling insect pests, and preventing transmission of insect borne diseases (Casida, 2009). In general, the pharmacological properties of insect native nAChRs are studied using electrophysiological approaches, with isolated neurons expressing nAChR subtypes (Thany et al., 2007; Barbara et al., 2008; Salgado, 2016). Cockroach neurons from thoracic ganglia and dorsal unpaired median (DUM) neurons are currently used to characterize the pharmacological properties of insect native nAChR subtypes, and the mode of action of neonicotinoid insecticides (Courjaret and Lapied, 2001; Courjaret et al., 2003; Calas-List et al., 2012; Salgado, 1998; Salgado and Saar, 2004; Thany et al., 2008). Using cockroach thoracic ganglia, two $\alpha$-bungarotoxin ( $\alpha$-Bgt)sensitive $\mathrm{nAChR}$ subtypes were characterized: $\mathrm{nAChD}$ and $\mathrm{nAChN}$. $\mathrm{nAChD}$ was desensitizing, and selectively inhibited by IMI, and $\mathrm{nAChN}$ was non-desensitizing, and selectively inhibited by methyllicaconitine (MLA) (Salgado, 2016; Salgado and Saar, 2004). Moreover, nAChD receptors are potently inhibited by neonicotinoid insecticides whereas $\mathrm{nAChN}$ are activated by neonicotinoids (Salgado and Saar, 2004). $\alpha$-Bgt-sensitive and -insensitive nAChR subtypes were also found in the DUM neurons. Two $\alpha$-Bgt-insensitive receptors were identified as nAChR1 and nAChR2. nAChR1 
was sensitive to imidacloprid, and selectively blocked by d-tubocurarine (d-TC), and nAChR2 was inhibited by mecamylamine (MEC) (Courjaret and Lapied, 2001; Courjaret et al., 2003; Thany et al., 2008; Bodereau-Dubois et al., 2012). Unfortunately, although detailed information is available concerning the pharmacological properties of cockroach native $\mathrm{nAChR}$ subtypes, the subunit combination of these receptors is unknown.

Genes encoding insect nAChR subunits were cloned from several insect species, including the fruit fly Drosophila melanogaster, the honey bee Apis mellifera and the mosquito Anopheles gambiae for which the genome is known. From comparison of the insect and vertebrate nAChR subunits it appeared that the monophyletic group including drosophila $\mathrm{D} \alpha 5, \mathrm{D} \alpha 6$ and $\mathrm{D} \alpha 7$, is closely related to mammalian $\alpha 7$ subunit (Thany et al., 2007). This group is of specific interest because mammalian $\alpha 7$ subunits form homomeric receptors which are currently used to study the pharmacology and functional properties of nAChR subtypes (Gill et al., 2013; Delbart et al., 2018). Binding investigations using nicotinic agonists showed that $\alpha 7 \mathrm{nAChR}$ mediates inward currents sensitive to $\mathrm{nAChR}$ antagonists such as $\alpha$-Bgt or MLA when applied coincidentally with agonists, or pre-exposed to antagonists before agonist application (Cuevas et al., 2000; Virginio et al., 2002; Zhao et al., 2003). A previous study suggests that members of this group could form homomeric receptors when they are expressed in heterologous systems (Lansdell et al., 2012). Indeed, despite there having been only limited success in expressing insect nAChR subunits, a direct expression of the drosophila $\mathrm{D} \alpha 7$ subunit in Xenopus laevis oocytes formed a functional receptor when it was co-expressed with the chaperone resistant to inhibitors of acetylcholinesterase (RIC-3) (Lansdell et al., 2012). However, no specific $\alpha$ Bgt binding was detected (Lansdell et al., 2012), suggesting that drosophila $\alpha 7$ receptors could be insensitive to $\alpha$-Bgt. Moreover, the drosophila $\mathrm{D} \alpha 5$ subunit was able to form a homomeric $\alpha$-Bgt-sensitive receptor when co-expressed with RIC-3 (Lansdell and Millar, 2004; Lansdell et al., 2012). Thus, the pharmacological properties of the $\alpha 7$ monophyletic group seemed to be more complex.

In the present study, we report the cloning and expression of a cockroach Pame 77 subunit in the Xenopus laevis oocytes. We show that Pame $\alpha 7$ subunit can form a functional receptor in the Xenopus oocytes.

\section{MATERIALS AND METHODS}

\section{Insects}

All experiments were performed with cockroach Periplaneta americana laboratory-reared insects.

\section{Compounds}

ACh, nicotine, MLA, MEC, d-TC and atropine were purchased from Sigma Chemical Co. (St Quentin, France). $\alpha$-Bgt was purchased from Biotrend (Köln, Germany).

\section{Bioinformatic Analysis}

Sequence alignment were made with BioEdit software and deduced amino acid sequences were analyzed using the ClustalW program (Thompson et al., 1994). The location of the functional domains was determined using TMHMM 2.0 software (Moller et al., 2001). nAChR subunit sequences used for phylogenetic analysis were downloaded from GenBank database ${ }^{1}$. A phylogenetic tree was constructed using neighbor-joining statistical method (Saitou and Nei, 1987) with Bootstrap test at 1,000 replications and $\mathrm{p}$-distance as substitution model. Branches corresponding to partitions reproduced in less than $50 \%$ bootstrap replicates were collapsed. The D. melanogaster GABAa subunit was used as outgroup. Analyses were conducted with the MEGA6 program (Tamura et al., 2013).

\section{RT-PCR Amplification, Cloning and Sequencing of the Cockroach Pame $\alpha 7$ Subunit}

Total RNA was isolated from adult brain using the RNeasy Mini Kit (Qiagen). RT-PCR and cDNA cloning was performed as follows: first-strand cDNA was product from $2 \mu \mathrm{g}$ of total RNA, incubated at $65^{\circ}$ for $5 \mathrm{~min}$ in the presence of $100 \mathrm{ng}$ oligodT, $0.5 \mathrm{mM}$ dNTP, $10 \mathrm{mM}$ DTT, 1x RT buffer. After adding $1 \mu \mathrm{l}$ of Superscript II RT (Invitrogen, Carlsbad, CA, United States), the reaction was proceeded at $42^{\circ}$ for $50 \mathrm{~min}$ and at $70^{\circ}$ for $10 \mathrm{~min}$. The complete Pame $\alpha 7 \mathrm{cDNA}$ sequence was amplified using the following sense and antisense primers: AAGGATCCCCAACCATGGA GTCAACAGCAGCCTCCGA (sense) and CAAAATCTAGATTACGTCACGATGATGTG GGGCG (antisense). PCR amplification conditions were: $94^{\circ} \mathrm{C}$ $2 \mathrm{~min}, 30$ cycles $\left(94^{\circ} \mathrm{C}\right.$ for $30 \mathrm{~s}, 65^{\circ} \mathrm{C}$ for $30 \mathrm{~s}, 72^{\circ} \mathrm{C}$ for $1 \mathrm{~min}$ $40 \mathrm{~s}$ ) and $72^{\circ} \mathrm{C}$ for $5 \mathrm{~min}$. PCR products were cloned in pGem vector (pGem T-easy vector system, Promega) and sequenced.

\section{Semi-Quantitative PCR Amplification}

For semi-quantitative PCR amplification, the following primers were used GATGGCTTCTCTTCGTCTGC (sense) and CAGCTACCGCTATCCCTGAC (antisense) for Pame $\alpha 7$ subunit. CTGACCCTTAAATACCCCATTG (sense) and CACAATTTCTCGTTCGGCAGTG (antisense) for actin. PCR was performed in a total volume of $25 \mu \mathrm{l}$ containing $1 \mu \mathrm{l}$ of RT products, $0.4 \mu \mathrm{M}$ of each primer, $0.2 \mathrm{mM}$ desoxyribonucleotide triphosphates (dNTP), $1.5 \mathrm{mM} \mathrm{MgCl}_{2}$ and $0.125 \mu \mathrm{l}$ of Taq polymerase (Invitrogen, Carlsbad, CA, United States). The following PCR conditions were used: 20 cycles at $95^{\circ} \mathrm{C}$ for $30 \mathrm{~s}, 58^{\circ} \mathrm{C}$ for $30 \mathrm{~s}, 72^{\circ} \mathrm{C}$ for $1 \mathrm{~min}$ and a final elongation of $72^{\circ} \mathrm{C}$ for $5 \mathrm{~min}$. Data were analyzed using image $\mathrm{J}$ software. Pame $\alpha 7$ expression level in each sample was normalized with the corresponding actin expression (Taillebois et al., 2014).

\section{In situ Hybridization}

In situ hybridization on cryostat frontal sections was performed with digoxigenin-labeled RNA probes (Sigma-Aldrich, France) as described previously (Thany et al., 2003; Thany and Gauthier,

\footnotetext{
${ }^{1}$ http://www.ncbi.nlm.nih.gov/genbank/
} 


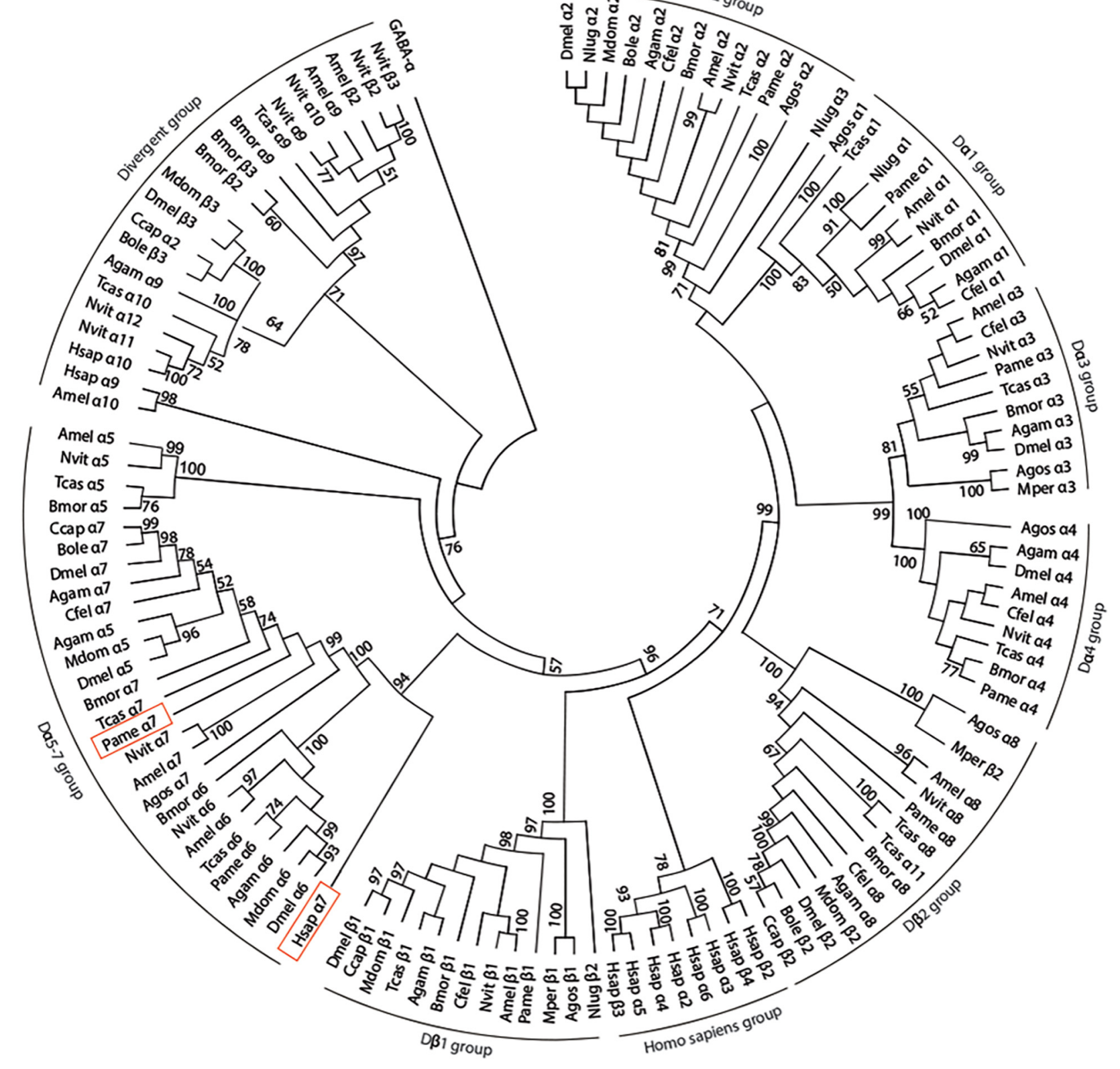

FIGURE 1 | Phylogenetic tree showing relationships of alpha 7 nAChR subunit protein sequence of the cockroach $P$. americana and its orthologs in several insect species and human. The bootstrap support value (\%) based on 1,000 replicates are shown when higher than $50 \%$. The $D$. melanogaster $\mathrm{GABA}_{A}$ subunit (accession number AAA28556.1) was used as outgroup. Accession sequence identifiers are as follows: Anopheles gambiae: Agama1 (AAU12503.1), Agama2 (AAU12504.1), Agama3 (XP_310786.3), Agama4 (XP_566274.3), Agama5 (XP_314691.2), Agama6 (XP_308042.3), Agama7 (XP_309153.3), Agama8 (XP_311925.3), Agama9 (XP_310203.3), Agam 1 1 (XP_309158.3); Aphis gossypii: Agosa1 (AAM94383.1), Agosa2 (AAM94382.1), Agosa3 (ABR21379.1), Agosa4 (ABR21380.1), Agosa7

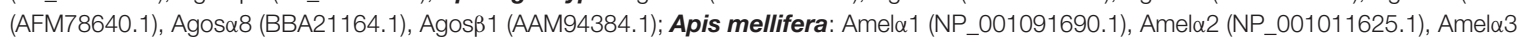
(NP_001073029.1), Amela4 (NP_001091691.1), Amela5 (AJE70263.1), Amela6 (NP_001073564.1), Amela7 (AJE70265.1), Amela8 (NP_001011575.1), Amela9

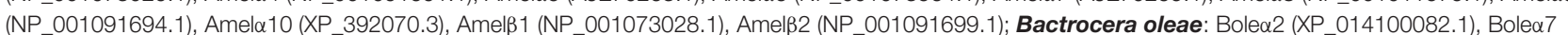

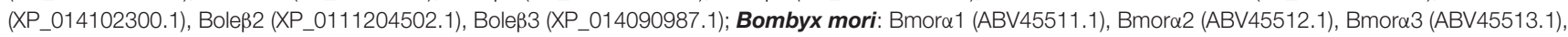
Bmora4 (ABV45514.1), Bmora5 (ABV45516.1), Bmora6 (NP_001091830.1), Bmora7 (ABV45520.2), Bmora8 (ABV45521.1), Bmora9 (ABV45523.1), Bmorß1

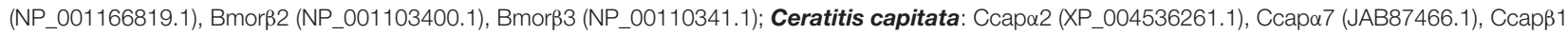
(XP_012156453.1), Сcapß2 (XP_012162675.1); Drosophila melanogaster: Dmela1 (CAA30172.1), Dmela2 (NP_524482.1), Dmela3 (CAA75688.1), Dmela4

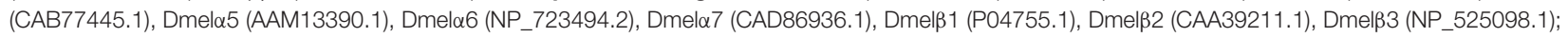

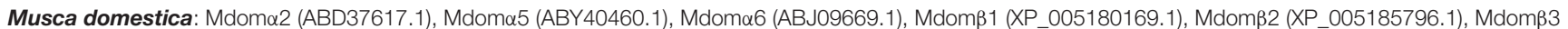
(ABY40465.1); Myzus persicae: Mpera3 (CAB52297.1), Mperß1 (XP_022165274.1), Mperß2 (XP_022167599.1); Nasonia vitripennis: Nvita1 (ACY82683.1), Nvita2 (ACY82684.1), Nvita3 (ACY82685.1), Nvita4 (ACY82686.1), Nvita5 (ACY82688.1), Nvita6 (ACY82689.1), Nvita7 (ACY82692.1), Nvita8 (ACY82693.1), Nvita9

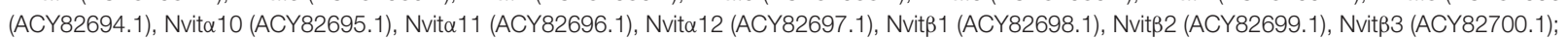


FIGURE 1 | Continued

Nilaparvata lugens; Nluga1 (AAQ75737.1), Nluga2 (AAQ7574101), Nluga3 (AAQ75739.1), NlugB2 (AAQ75742.2); Periplaneta americana: Pamea1 (AKV94620.1), Pamea2 (AKV94621.1), Pamea3 (AKR16132.1), Pamea4 (AFA28129.1), Pame 6 (AKV94622.1), Pame 7 (MK790056), Pame 8 (AFA28130.1), Pameß1 (AKV94624.1); Tribolium castaneum: Tcas 1 (ABS86902.1), Tcas $\alpha 2$ (ABS86903.1), Tcas $\alpha 3$ (ABS86904.1), Tcas $\alpha 4$ (ABS86905.1), Tcas $\alpha 5$ (ABS86907.1), Tcas $\alpha 6$ (ABS86908.1), Tcas $\alpha 7$ (ABS86911.1), Tcas $\alpha 8$ (ABS86912.1), Tcas $\alpha 9$ (ABS86913.1), Tcas $\alpha 10$ (ABS86914.1), Tcas $\alpha 11$ (ABS86915.1), Tcas $\beta 1$ (ABS86916.1); Homo sapiens: Hsapa2 (AAB40109.1), Hsapa3 (AAA59942.1), Hsapa4 (AAA64743.1), Hsapa5 (AAA58357.1), Hsapa6 (AAB40113.1), Hsapa7 (CAA49778.1), Hsapa9 (CAB65091.1), Hsapa10 (CAC20435.1), Hsapß2 (CAA37320.1), Hsapß3 (CAA47851.1), Hsapß4 (CAA48336.1); Ctenocephalides felis: Cfela1 (ABB42999), Cfela2 (ABB43000), Cfela3 (ABB43001), Cfela4 (ABB43003), Cfela7 (ABB43004), Cfela8 (ABB43002), Cfelß1 (ABB43005).

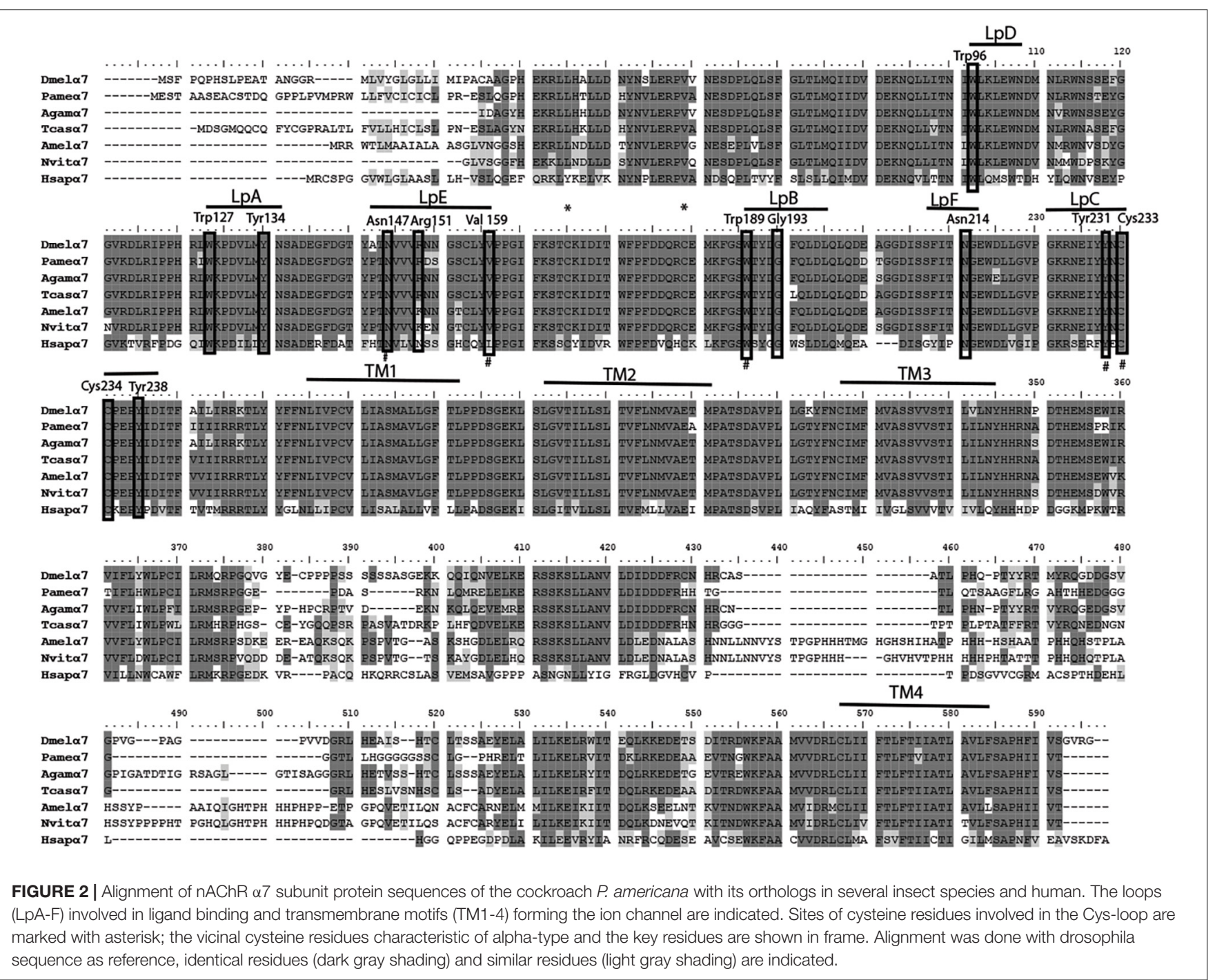

2005). A cDNA fragment of $1.6 \mathrm{~Kb}$ corresponding to Pame $\alpha 7$ was cloned in pCR 4-TOPO vector (ThermoFisher Scientific, France) with HindIII and XhoI restriction enzymes. After linearization with NotI, in vitro transcription was performed with T7 RNA polymerase to generate antisense DIG-labeled RNA probes.

\section{Preparation of cDNA for Expression in the Xenopus Oocytes}

Cockroach Pamea7 (GenBank accession number: JX466891) subunit was cloned into XbaI/BamHI (Invitrogen, Carlsbad, CA, United States) digested pGEM-HEJUEL plasmid (Provided by Prof. Olaf Pongs, Institute for Neural Signal Transduction, Germany, to Prof Christian Legros, University of Angers, France) as previously described (Bourdin et al., 2015). pGEM contains both $5^{\prime}$ and $3^{\prime}$ UTR from the Xenopus beta-globin gene, allowing high expression of foreign protein in Xenopus oocytes.

\section{Oocyte Injection in the Xenopus Laevis Oocytes}

Xenopus laevis oocytes were obtained from the CRB xenope, University of Rennes, France. The CRB xenope is a French national platform dedicated to xenopus breeding for 


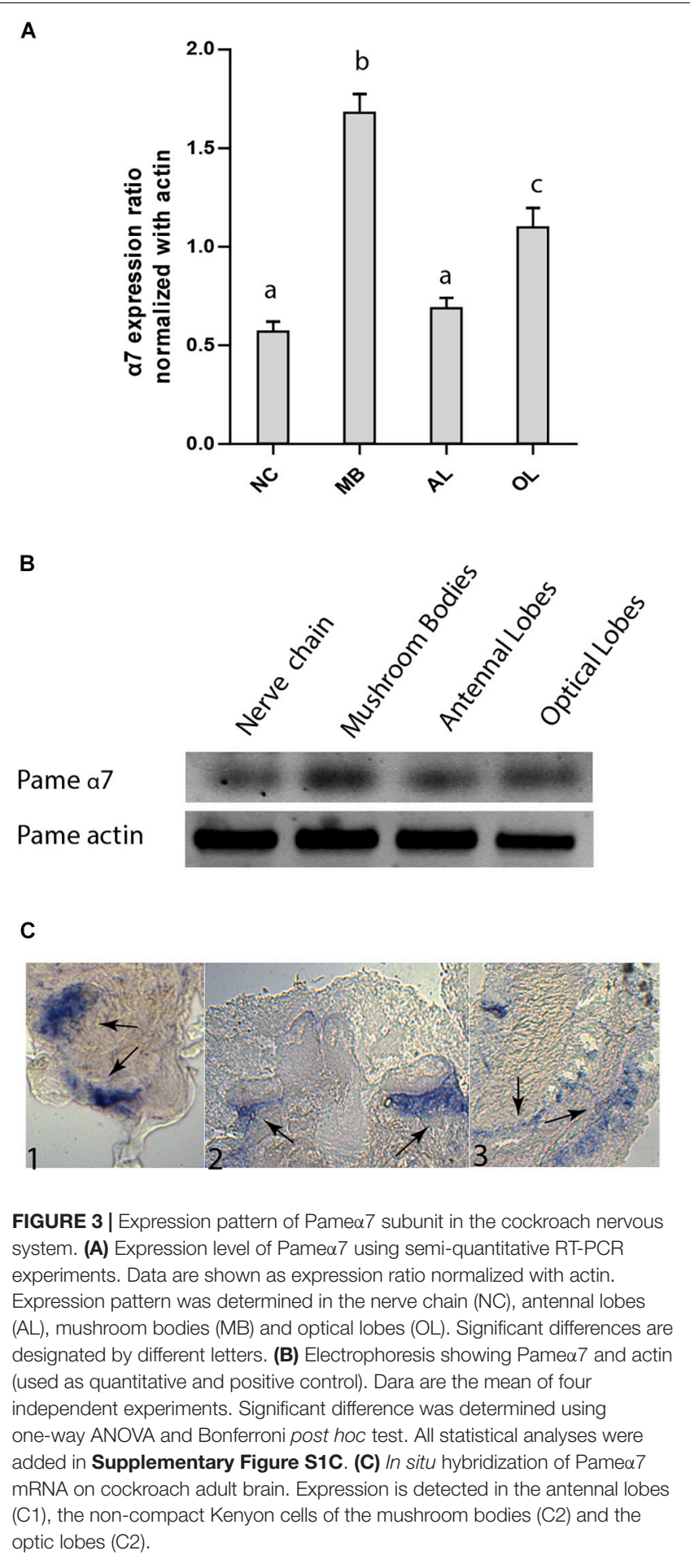

experimental research. Xenopus laevis oocytes were stored in a standard oocyte saline solution (SOS) of the following composition: in $\mathrm{mM}, 100 \mathrm{NaCl}, 2 \mathrm{KCl}, 1 \mathrm{MgCl} 2,1.8 \mathrm{CaCl}_{2}$ and 5 HEPES, pH 7.5. Stage V and VI oocytes were harvested and defolliculated after treatment with $2 \mathrm{mg} / \mathrm{ml}$ collagenase IA (Sigma, France) in $\mathrm{Ca}^{2+}$-free SOS solution, supplemented with $0.8 \mathrm{mg} / \mathrm{ml}$ trypsin inhibitor. Defolliculated oocytes were injected with 2 ng of $\alpha 7$ cDNA cloned in pGEM (Couturier et al., 1990; Ihara et al., 2003). Injected oocytes were maintained at $18^{\circ} \mathrm{C}$ in SOS solution supplemented with penicillin $(100 \mathrm{U} / \mathrm{ml})$, streptomycin $(100 \mathrm{mg} / \mathrm{ml})$, gentamycin $(50 \mathrm{mg} / \mathrm{ml})$ and sodium pyruvate $(2.5 \mathrm{mM})$.

\section{Voltage-Clamp Recordings}

Currents were recorded 4 days after injection, using two microelectrodes filled with $3 \mathrm{M} \mathrm{KCl}$. The oocyte membrane potential was held at $-80 \mathrm{mV}$ (Taylor-Wells et al., 2017), and perfused continuously with recording buffer at room temperature $\left(20-22^{\circ} \mathrm{C}\right)$. To suppress potential endogenous muscarinic responses, saline solution containing $0.5 \mu \mathrm{M}$ atropine was employed (Matsuda et al., 1998, 2000). The dose response curves were estimated by using increasing concentrations of the compounds on the same oocyte. Oocytes were challenged with a test compound at $5 \mathrm{~min}$ intervals to minimize receptor desensitization (Ihara et al., 2003). To assess the pharmacological profile of these receptors, experiments were conducted with different antagonists. Experimental data was digitized with a Digidata-1322A A/D converter and then analyzed with pCLAMP (Molecular Devices, Union City, CA, United States). All compound solutions were prepared using the recording buffer.

\section{Statistical Analysis}

For statistical analysis of Pame 7 expression levels, one-way ANOVA and Bonferroni post hoc test were employed. All currents were shown as mean \pm SEM and analyzed using Prism 7 (GraphPad Software, La Jolla, CA, United States). Note that for all compounds, experiments were also performed on non-injected oocytes to avoid native responses (data not shown). Oocytes were assigned to each group without knowledge of the treatments (blinded). The dose response curves were derived from the fitted curve following the equation: $Y=\mathrm{I}_{\text {min }}+\left(\mathrm{I}_{\max }-\mathrm{I}_{\min }\right) /\left(1+10^{(\log (E C 50 X) H)}\right)$ where $Y$ is the normalized response, $I_{\max }$ and $\mathrm{I}_{\min }$ are the maximum and minimum responses, $\mathrm{H}$ is the Hill coefficient, $\mathrm{EC}_{50}$ is the concentration giving half the maximum response and $X$ is the logarithm of the compound concentration. For the electrophysiological recordings, " $n$ " represents the number of experiments. Thus, currents were analyzed using the Kruskalwallis one-way ANOVA and Bonferroni post hoc test. $P<0.05$ was the minimum level of significance.

\section{RESULTS}

\section{Cloning and Expression Pattern of Cockroach $\alpha 7$ Subunit in the Nervous System}

We have amplified by a nested PCR approach using putative cockroach Periplaneta americana $\alpha 7$ subunit sequences (JX466891 and JF731242) available in the GenBank database a full Pame 7 cDNA sequence. Two independent clones were obtained and sequenced, one encoded for a truncated form 
A

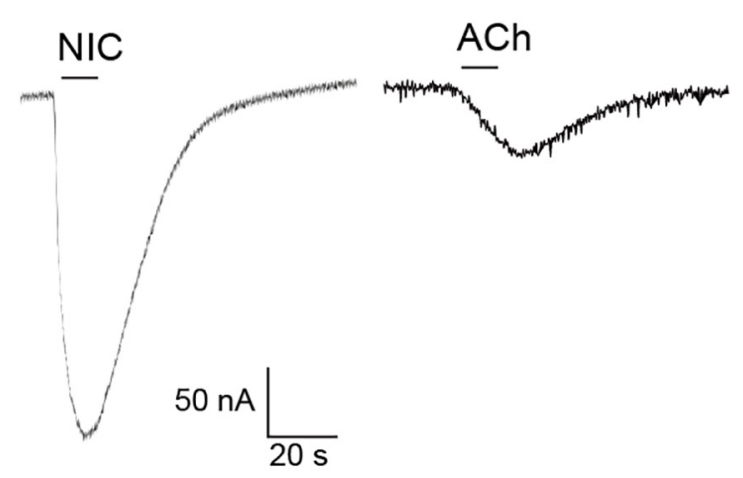

B

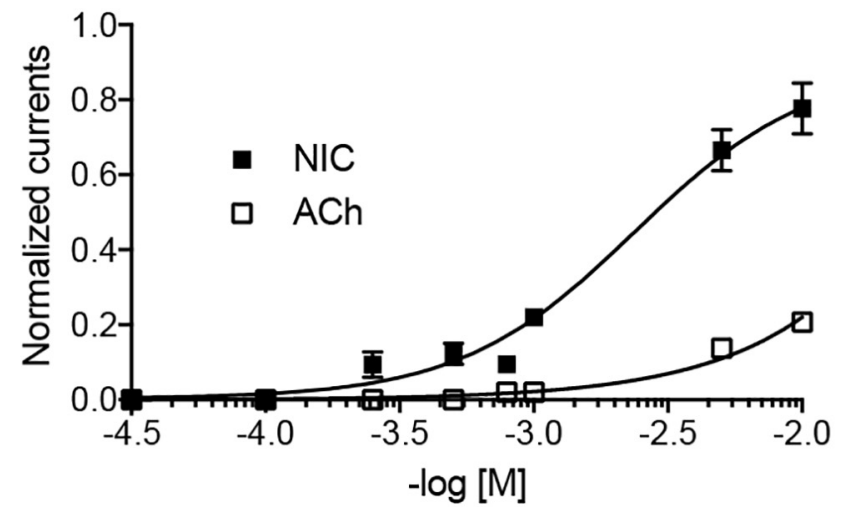

C

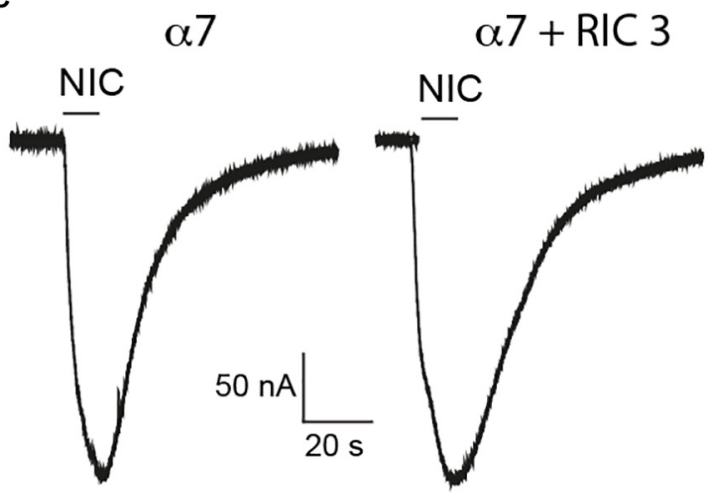

D

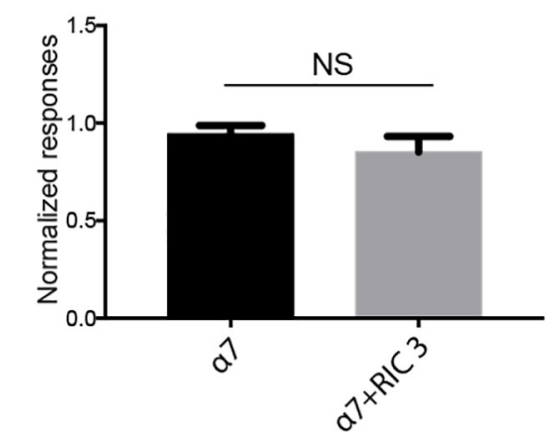

FIGURE 4 | Effect of nicotine (Nic) and acetylcholine (ACh) on cockroach a7 nAChRs expressed in Xenopus laevis oocytes. (A) Typical example of nicotine- and acetylcholine-induced currents. Currents are recorded at $10 \mathrm{mM}$ nicotine or acetylcholine, respectively. (B) Dose-response curve are represented for nicotine and acetylcholine. Data are normalized to $10 \mathrm{mM}$ nicotine and each point represents a mean \pm S.E.M of $n=12$ tested oocytes. (C,D) Nicotine (10 mM) evoked currents recorded after the expression of cockroach $\alpha 7$ subunit alone or with rat RIC-3. Each histogram represents mean \pm S.E.M of $n=10$ oocytes. NS $=$ no significant difference using one-way ANOVA and Bonferroni post hoc test.

of Pamea7 (data not shown) and a complete cDNA sequence of Pame 7 subunit (GenBank accession number MK790056) with 1554 bp in length (Cartereau, 2018). This ORF encoded a protein of 518 amino acids with a predicted molecular weight of $58.02 \mathrm{kDa}$, and an estimated $\mathrm{p} I$ of 5.45 . Comparison of our cloned sequence with putative cockroach $\alpha 7$ sequences available in the GenBank database revealed 98\% sequence homology. Additional putative subunit sequences of the cockroach were identified and help us to propose a phylogenetic tree and homogenate nomenclature (Figure 1). Phylogenetic analysis with insect and mammalian nAChR subunits demonstrated that Pame $\alpha 7$ was included in the $\mathrm{D} \alpha 5-\mathrm{D} \alpha 7$ group which was defined as closed to the mammalian $\alpha 7$ subunit. The present Pame $\alpha 7$ subunit nomenclature takes this fact into account. We also found two distinct clusters formed by insect $\beta$ subunits and a divergent cluster formed by $\mathrm{nAChR}$ subunits from different insect species (Figure 1). Moreover, amino acid sequence alignment showed that Pame $\alpha 7$ has features typical of the $\alpha$ subunit nAChR family. It contains the functional domains and key amino acids for agonist binding. The four hydrophobic putative transmembrane domains TM1-TM4, the two adjacent cysteines, and extracellular loops (LpA-F) as well as key amino acid residues (Asn147,
Trp189, Tyr231,Cys233-234) (Shimomura et al., 2004; Yao et al., 2009; Wu et al., 2015) which are highly conserved between insect and human $\alpha$ nAChR subunits. Except for Val159 which seemed specific to insect species. In addition, the amino acid sequences between TM3 and TM4 appears highly variable (Figure 2). To further investigate the expression of Pame $\alpha 7$ in the cockroach nervous system, we compared its expression level in several nervous tissues (Figures $\mathbf{3 A}, \mathbf{B}$ ). Semi-quantitative PCR experiments highlighted a strong expression in mushroom bodies and optical lobes compared to antennal lobes and nerve chain. In the MBs, using Pame $\alpha 7$-specific RNA probes, we found an expression in outer Kenyon cells of the MBs, in the cells between the lamina and the lobula, and in some cells of the antennal lobes (Figure 3C). Substantial analyses comparing RT-PCR conditions after several PCR cycles were added in the Supplementary Figures S1A,B and Supplementary Table S1).

\section{Expression of Pame $\alpha 7$ Subunit in Xenopus laevis Oocytes}

The functional expression of the cockroach $\alpha 7$ homomeric receptor was first studied using direct expression of the Pamea7 subunit in Xenopus laevis oocytes. The functional 


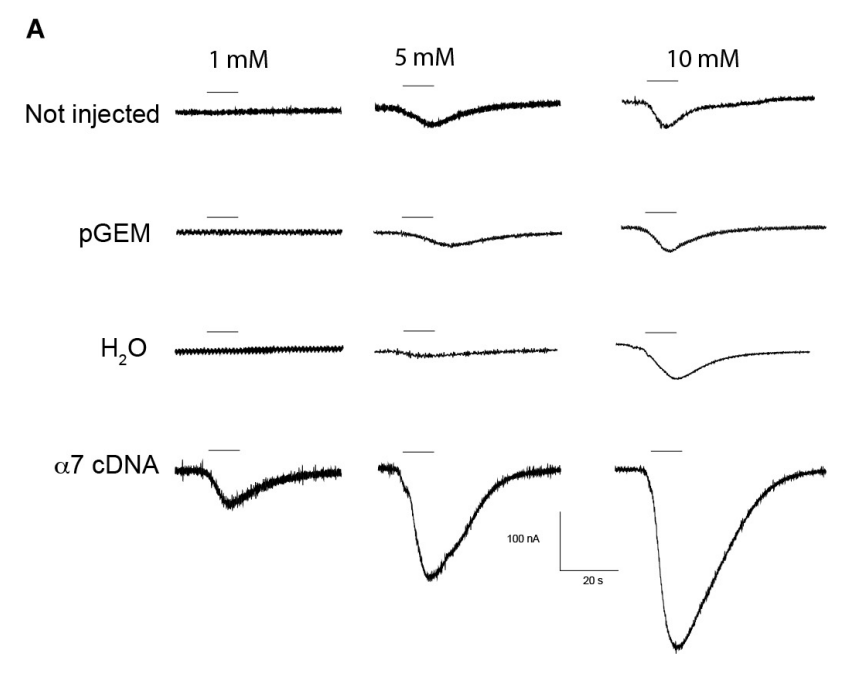

B

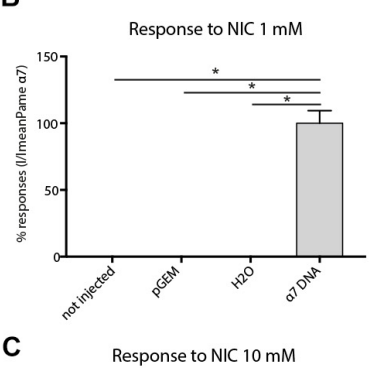

C

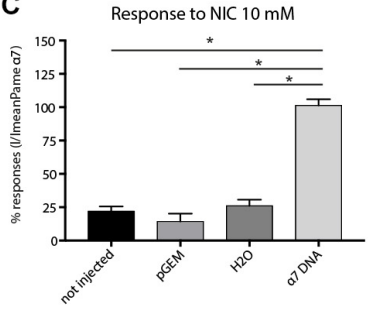

D

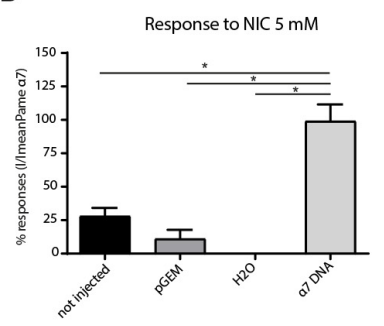

FIGURE 5 | Comparative effect of nicotine on different experimental conditions. (A) Typical examples of nicotine-induced currents on not injected oocytes (native oocytes), oocytes with only water, oocytes with pGem vector and oocytes with a7 cDNA. Bars indicate $10 \mathrm{~s}$ application of nicotine at 1, 5 or 10 mM. (B-D) Histograms summarize applications of nicotine at different experimental conditions. Each histogram represents $n=12$ oocytes, ${ }^{\star} p<0.05$ using One-way ANOVA and Bonferroni post hoc test.

expression of cockroach $\alpha 7$ homomeric receptor was first studied using direct expression of $\alpha 7$ subunit in the Xenopus laevis oocytes. ACh and nicotine induced inward currents but nicotine activated Pame 77 receptors in a dose-dependent manner and the maximum responses with nicotine were greater than the maximum responses evoked by ACh (Figures 4A,B). At $10 \mathrm{mM}$, the max currents for nicotine and ACh were $-212 \pm 0.13$ and $-56 \pm 09 \mathrm{nA}$, respectively. The $\mathrm{EC}_{50}$ for Nicotine was $790 \mu \mathrm{M}$ whereas for $\mathrm{ACh}$, we were not able to calculate it. Co-expression of cockroach Pame 27 subunit with a rat RIC-3 did not enhance or change the response induced by nicotine (Figures 4C,D, $n=18, p>0.05$ ). We proposed that rat RIC-3 is not necessary for the functional expression of Pame $\alpha 7$ receptor and that Pame 27 subunit can form a functional homomeric receptor alone. Moreover, we found also that Pame $\alpha 7$ cDNA formed a functional receptor compared to Pame 27 cRNA (see Supplementary Figure S1C). Thus, we used Pame $\alpha 7$ cDNA, as described in previous studies (Hurst et al., 2005; Moroni et al., 2006; Alcaino et al., 2017). In addition, we decided to select as a test concentration $10 \mathrm{mM}$ nicotine, in consistency with the conditions used for cockroach DUM neurons expressing $\mathrm{nAChR}$ subtypes (Courjaret and Lapied, 2001; Courjaret et al., 2003) and because currents induced by ACh were low to conduct a robust analysis. We then tested the effect of nicotine on oocytes containing water and pGem vector. As illustrated in Figure 5, despite that native currents were recorded when we used 5 or $10 \mathrm{mM}$ nicotine, currents induced following $10 \mathrm{~s}$ application of $1 \mathrm{mM}$ nicotine demonstrated that Pame 7 cDNA injection expressed a functional receptor in the oocytes. The percentage of successful expression of cockroach Pame $\alpha 7$ receptors that respond to nicotine applications was around 75\% ( $n=120$ tested oocytes at $1 \mathrm{mM}$ nicotine). The $\mathrm{I}_{\max }$ values at $1 \mathrm{mM}$ nicotine was $-92 \pm 27 \mathrm{nA}$. Moreover, bath application of $10 \mu \mathrm{M} \alpha$-Bgt, did not block or reduce nicotine-evoked currents (Figure 6A, $n=10$ cells, $p>0.05$, one-way ANOVA and Bonferroni post hoc test) but MLA, a potent specific nicotinic antagonist of vertebrate neuronal $\alpha 7$ nAChRs (Davies et al., 1999), reduced $24 \%$ of the nicotine evoked currents (Figure 6B, $n=12, p<0.05$, oneway ANOVA and Bonferroni post hoc test). Additional data were performed to investigate if MLA reduced currents on not injected eggs. MLA has no effect on not injected oocytes (see Supplementary Figure S1D). In addition, no blocking or reduction of nicotine currents was found with $5 \mu \mathrm{M}$ MEC (Figure 6C, $n=8, p>0.05$, one-way ANOVA and Bonferroni post hoc test) or $10 \mu \mathrm{M} \mathrm{d}$-TC (Figure 6D, $n=8, p>0.05$, one-way ANOVA and Bonferroni post hoc test).

\section{DISCUSSION}

We have cloned using putative sequence available in the GenBank database a DNA fragment corresponding to the cockroach Pame $\alpha 7$. The cDNA for Pame $\alpha 7$ encodes a protein sequence of 518 amino acids which is closely related to the human $\alpha 7$ subunit. Temporal and spatial expression of Pame $\alpha 7$ mRNA demonstrated a specific expression in the MBs. This tissue specific expression was also found with other insects using in situ hybridization of transcripts from the honey bee Amel $\alpha 7$. Indeed, Amel $\alpha 7$ was also expressed in the antennal lobes and optic lobes. Expression in the MBs was found in the outer and non-compact Kenyon cells (Thany et al., 2005).

We then studied the expression of the Pamea7 subunit in the Xenopus laevis oocytes and found that it can form functional homomeric receptors in the Xenopus laevis oocytes. To date functional expressions of an insect homomeric $\alpha$ receptor had been demonstrated in Xenopus laevis oocytes with the 
A

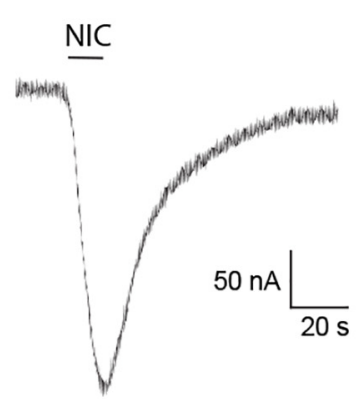

B

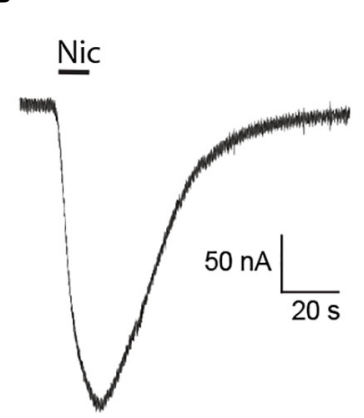

C

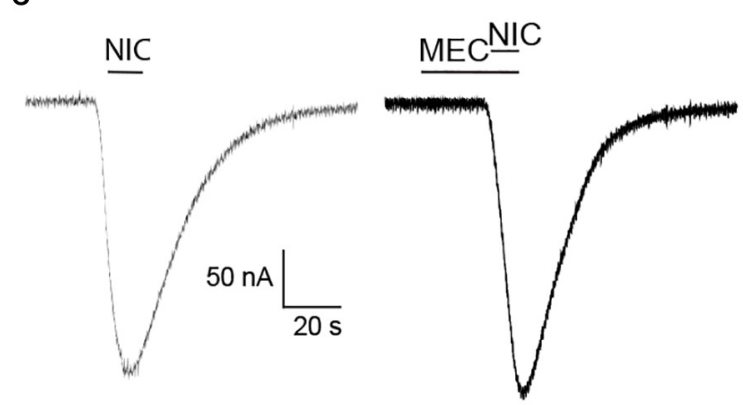

D

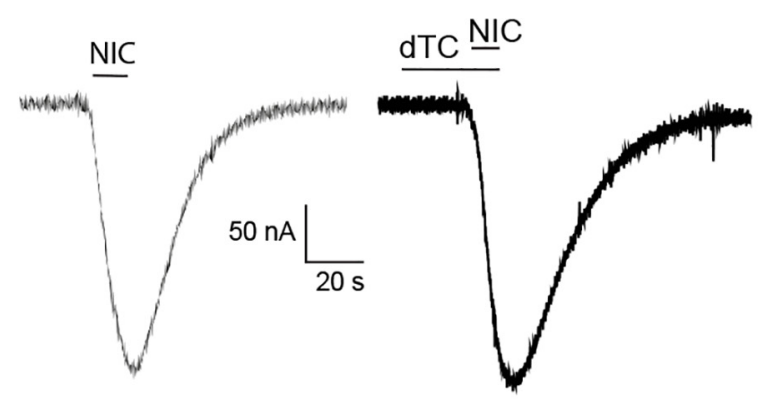

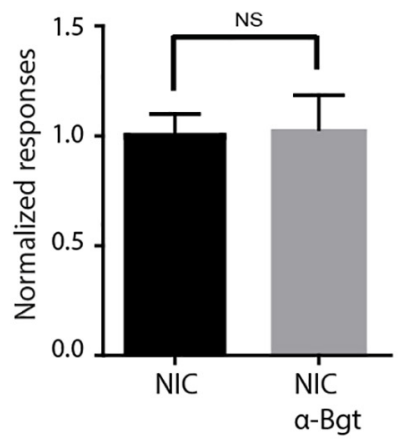
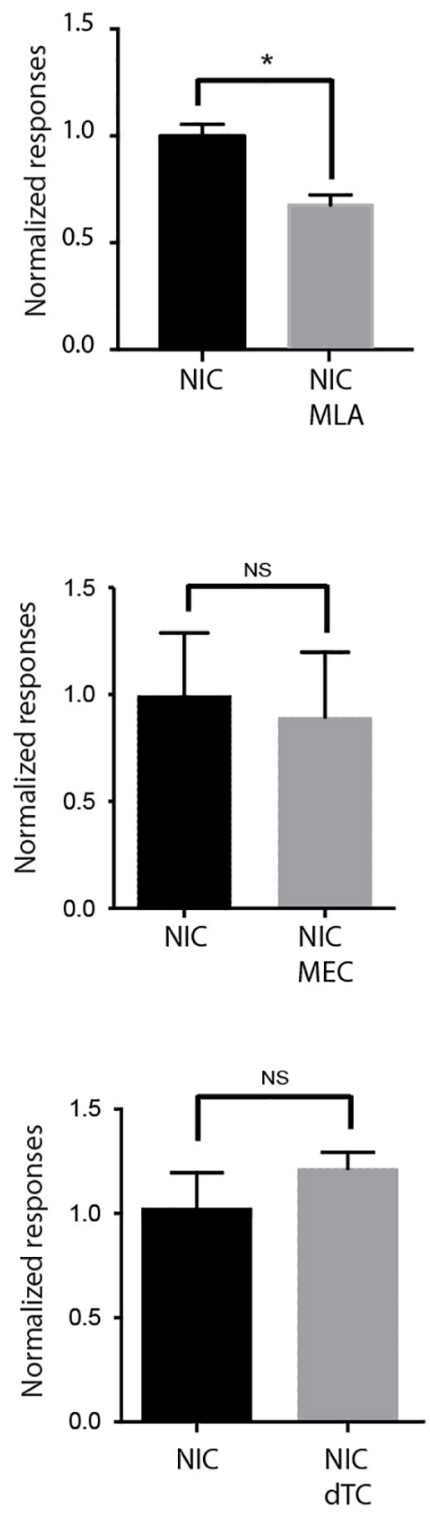

FIGURE 6 | Effect of $\mathrm{nAChR}$ antagonists on nicotine evoked currents. (A) 5 min pretreatment with $10 \mu \mathrm{M} \alpha-\mathrm{Bgt}$, (B) $10 \mu \mathrm{M}$ MLA, (C) $5 \mu \mathrm{M}$ mecamylamine (MEC), and (D) $10 \mu \mathrm{M}$ d-TC. Bars indicate application of $10 \mathrm{~s}$ nicotine at $10 \mathrm{mM}$. Histograms illustrate the effect of each antagonist on nicotine-evoked currents. In each case, data are mean \pm S.E.M of $n=12$ oocytes, ${ }^{*} p<0.05$ using one-way ANOVA and Bonferroni post hoc test. NS = no significant. 
Drosophila melanogaster $\mathrm{D} \alpha 5$ and $\mathrm{D} \alpha 7$ subunits co-expressed with the molecular chaperone CeRIC-3. Our investigations suggest that the cockroach Pame $\alpha 7$ receptor is insensitive to $\alpha$ Bgt. This result was not surprising as there was also a lack of specific $\alpha$-Bgt binding sites on drosophila S2 cells, expressing fulllength $\mathrm{D} \alpha 6$ or $\mathrm{D} \alpha 7$ subunits. The only exception were the use of chimeric $\mathrm{D} \alpha 6 / 5 \mathrm{HT}_{3 A}$ and $\mathrm{D} \alpha 7 / 5 \mathrm{HT}_{3 A}$ receptors or recombinant $\mathrm{D} \alpha 6$ and $\mathrm{D} \alpha 7$ receptors expressed with RIC-3 (Lansdell and Millar, 2004; Lansdell et al., 2012). Moreover, cockroach Periplaneta americana did not express an $\alpha 5$ subunit compared to other insect species such as Drosophila melanogaster. Similar lack of $\alpha 5$ subunit ortholog was also shown in the pea aphid Acyrthosiphon pisum (Dale et al., 2010). The lack of this subunit may impact the expression and the functional properties of $\alpha 7$ subunit because it can form an heteromeric receptor with $\alpha 7$ subunit as found with Drosophila melanogaster.

In conclusion, in the present study, the challenge was to identify a cockroach Pame $\alpha 7$ subunit which was able to express functional receptor from direct expression in the Xenopus oocytes. But, we are aware that additional efforts are needed because we have to consider that currents are low when we use low acetylcholine and nicotine concentrations. Indeed, at low concentration, we did not find endogenous responses following application of nicotine (at $1 \mathrm{mM}$ ). At high nicotine (5 and $10 \mathrm{mM}$ ) concentrations, despite that currents are high, endogenous currents were found which lead us to be care on the results. Nevertheless, with all due caution, we consider that Pame 27 subunit can form functional homomeric receptor. Moreover, The low sensitivity could suggest that Pame $\alpha 7$ needs cockroach chaperone proteins like RIC-3 or NACHO (Gu et al., 2016). We have started to clone cockroach orthologs of RIC3 and the nAChR regulator, NACHO which we hope will help increasing currents through cockroach Pame $\alpha 7$ receptors. Indeed, despite that the mammalian RIC-3 increases $\alpha 7$ activity, it is not sufficient for efficient assembly of $\alpha 7$ but NACHO can synergize with RIC-3 for $\alpha 7$-type nAChRs surface expression (Matta et al., 2017). In addition to the cloning of RIC-3 and $\mathrm{NACHO}$, we aim to study the involvement of lynx proteins identified in Locusta migratoria, in particular lynx3 which

\section{REFERENCES}

Alcaino, C., Musgaard, M., Minguez, T., Mazzaferro, S., Faundez, M., IturriagaVasquez, P., et al. (2017). Role of the Cys loop and transmembrane domain in the allosteric modulation of alpha4beta2 nicotinic acetylcholine receptors. J. Biol. Chem. 292, 551-562.

Bao, H., Zhang, Y., Liu, Y., Yu, N., and Liu, Z. (2017). The functional interaction between nicotinic acetylcholine receptors and Ly-6/neurotoxin proteins in Locusta migratoria. Neurochem. Int. 108, 381-387.

Barbara, G. S., Grunewald, B., Paute, S., Gauthier, M., and Raymond-Delpech, V. (2008). Study of nicotinic acetylcholine receptors on cultured antennal lobe neurones from adult honeybee brains. Invert Neurosci. 8, 19-29.

Bodereau-Dubois, B., List, O., Calas-List, D., Marques, O., Communal, P. Y., Thany, S. H., et al. (2012). Transmembrane potential polarization, calcium influx, and receptor conformational state modulate the sensitivity of the imidacloprid-insensitive neuronal insect nicotinic acetylcholine receptor to neonicotinoid insecticides. J. Pharmacol. Exp. Ther. 341, 326-339.

Bourdin, C. M., Lebreton, J., Mathe-Allainmat, M., and Thany, S. H. (2015). Pharmacological profile of zacopride and new quaternarized fluorobenzamide increased epibatidine-evoked current amplitudes when it was coexpressed with both Loc $\alpha 1$ and rat $\beta 2$ or Loc $\alpha 4$ and rat $\beta 2$ in the Xenopus oocytes (Bao et al., 2017). All these studies will be our future goal.

\section{DATA AVAILABILITY STATEMENT}

The datasets generated for this study can be found in the GenBank accession number: JX466891.

\section{ETHICS STATEMENT}

All the experiments were performed with laboratory-reared insect. No special permit was required. All European guidelines for the care and use of laboratory animals were followed.

\section{AUTHOR CONTRIBUTIONS}

ST and J-YL designed the experiments. AC, ET, and CM performed the experiments. AC, ET, BS, JG, J-YL, and ST analyzed the data and wrote the manuscript.

\section{FUNDING}

This work was supported by grants from the Région Centre Val de Loire "SCREENROBOT project," from the Région Pays de la Loire "ECRIN project," and a Ph.D. grant for AC from the Région Centre Val de Loire.

\section{SUPPLEMENTARY MATERIAL}

The Supplementary Material for this article can be found online at: https://www.frontiersin.org/articles/10.3389/fphys. 2020.00418/full\#supplementary-material

analogues on mammalian alpha7 nicotinic acetylcholine receptor. Bioorg. Med. Chem. Lett. 15, 3184-3188.

Calas-List, D., List, O., and Thany, S. H. (2012). Nornicotine application on cockroach dorsal unpaired median neurons induces two distinct ionic currents: implications of different nicotinic acetylcholine receptors. Neurosci. Lett. 14, 64-68.

Cartereau, A. (2018). Caractérisation Des Sous-Types de Récepteurs Nicotiniques Neuronaux d'Insectes et Étude de la Modulation de Leurs Profils Pharmacologiques par les Insecticides Néonicotinoïdes. Dissertation thesis, University of Orléans, Orléans.

Casida, J. E. (2009). Pest toxicology: the primary mechanisms of pesticide action. Chem. Res. Toxicol. 22, 609-619.

Courjaret, R., Grolleau, F., and Lapied, B. (2003). Two distinct calcium-sensitive and -insensitive PKC up- and down-regulate an alpha-bungarotoxin-resistant nAChR1 in insect neurosecretory cells (DUM neurons). Eur. J. Neurosci. 17, 2023-2034.

Courjaret, R., and Lapied, B. (2001). Complex intracellular messenger pathways regulate one type of neuronal alpha-bungarotoxin-resistant nicotinic acetylcholine receptors expressed in insect neurosecretory 
cells (dorsal unpaired median neurons). Mol. Pharmacol. 60 , 80-91.

Couturier, S., Bertrand, D., Matter, J. M., Hernandez, M. C., Bertrand, S., Millar, N., et al. (1990). A neuronal nicotinic acetylcholine receptor subunit (alpha 7) is developmentally regulated and forms a homo-oligomeric channel blocked by alpha-BTX. Neuron 5, 847-856.

Cuevas, J., Roth, A. L., and Berg, D. K. (2000). Two distinct classes of functional 7 -containing nicotinic receptor on rat superior cervical ganglion neurons. J. Physiol. 525(Pt 3), 735-746.

Dale, R. P., Jones, A. K., Tamborindeguy, C., Davies, T. G., Amey, J. S., Williamson, S., et al. (2010). Identification of ion channel genes in the Acyrthosiphon pisum genome. Insect. Mol. Biol. 19(Suppl. 2), 141-153.

Davies, A. R., Hardick, D. J., Blagbrough, I. S., Potter, B. V., Wolstenholme, A. J., and Wonnacott, S. (1999). Characterisation of the binding of $[3 \mathrm{H}]$ methyllycaconitine: a new radioligand for labelling alpha 7-type neuronal nicotinic acetylcholine receptors. Neuropharmacology. 38, 679-690.

Delbart, F., Brams, M., Gruss, F., Noppen, S., Peigneur, S., Boland, S., et al. (2018). An allosteric binding site of the alpha7 nicotinic acetylcholine receptor revealed in a humanized acetylcholine-binding protein. J. Biol. Chem. 293, 2534-2545.

Gill, J. K., Chatzidaki, A., Ursu, D., Sher, E., and Millar, N. S. (2013). Contrasting properties of alpha7-selective orthosteric and allosteric agonists examined on native nicotinic acetylcholine receptors. PLoS ONE 8:e55047. doi: 10.1371/ journal.pone.0055047

Gu, S., Matta, J. A., Lord, B., Harrington, A. W., Sutton, S. W., Davini, W. B., et al. (2016). Brain alpha7 nicotinic acetylcholine receptor assembly requires NACHO. Neuron. 89, 948-955.

Hurst, R. S., Hajos, M., Raggenbass, M., Wall, T. M., Higdon, N. R., Lawson, J. A., et al. (2005). A novel positive allosteric modulator of the alpha7 neuronal nicotinic acetylcholine receptor: in vitro and in vivo characterization. J. Neurosci. 25, 4396-4405.

Ihara, M., Matsuda, K., Otake, M., Kuwamura, M., Shimomura, M., Komai, K., et al. (2003). Diverse actions of neonicotinoids on chicken alpha7, alpha4beta2 and Drosophila-chicken SADbeta2 and ALSbeta2 hybrid nicotinic acetylcholine receptors expressed in Xenopus laevis oocytes. Neuropharmacology 45, 133-144.

Lansdell, S. J., Collins, T., Goodchild, J., and Millar, N. S. (2012). The Drosophila nicotinic acetylcholine receptor subunits Dalpha5 and Dalpha7 form functional homomeric and heteromeric ion channels. BMC Neurosci. 13:73. doi: 10.1186/ 1471-2202-13-73

Lansdell, S. J., and Millar, N. S. (2004). Molecular characterization of Dalpha6 and Dalpha7 nicotinic acetylcholine receptor subunits from Drosophila: formation of a high-affinity alpha-bungarotoxin binding site revealed by expression of subunit chimeras. J. Neurochem. 90, 479-489.

Matsuda, K., Buckingham, S. D., Freeman, J. C., Squire, M. D., Baylis, H. A., and Sattelle, D. B. (1998). Effects of the alpha subunit on imidacloprid sensitivity of recombinant nicotinic acetylcholine receptors. Br. J. Pharmacol. 123, 518-524.

Matsuda, K., Shimomura, M., Kondo, Y., Ihara, M., Hashigami, K., Yoshida, N., et al. (2000). Role of loop D of the alpha7 nicotinic acetylcholine receptor in its interaction with the insecticide imidacloprid and related neonicotinoids. $\mathrm{Br}$. J. Pharmacol. 130, 981-986.

Matta, J. A., Gu, S., Davini, W. B., Lord, B., Siuda, E. R., Harrington, A. W., et al. (2017). NACHO mediates nicotinic acetylcholine receptor function throughout the brain. Cell Rep. 19, 688-696.

Moller, S., Croning, M. D., and Apweiler, R. (2001). Evaluation of methods for the prediction of membrane spanning regions. Bioinformatics 17, 646-653.

Moroni, M., Zwart, R., Sher, E., Cassels, B. K., and Bermudez, I. (2006). alpha4beta2 nicotinic receptors with high and low acetylcholine sensitivity: pharmacology, stoichiometry, and sensitivity to long-term exposure to nicotine. Mol. Pharmacol. 70, 755-768.

Saitou, N., and Nei, M. (1987). The neighbor-joining method: a new method for reconstructing phylogenetic trees. Mol. Biol. Evol. 4, $406-425$.

Salgado, V. L. (1998). Studies on the mode of action of spinosad: insect symptoms and physiological correlates. Pest Biochem. Physiol. 60, 91-102.

Salgado, V. L. (2016). Antagonist pharmacology of desensitizing and nondesensitizing nicotinic acetylcholine receptors in cockroach neurons. Neurotoxicology 56, 188-195.
Salgado, V. L., and Saar, R. (2004). Desensitizing and non-desensitizing subtypes of alpha-bungarotoxin-sensitive nicotinic acetylcholine receptors in cockroach neurons. J. Insect. Physiol. 50, 867-879.

Shimomura, M., Yokota, M., Matsuda, K., Sattelle, D. B., and Komai, K. (2004). Roles of loop C and the loop B-C interval of the nicotinic receptor alpha subunit in its selective interactions with imidacloprid in insects. Neurosci. Lett. 363, 195-198.

Taillebois, E., Beloula, A., Quinchard, S., Jaubert-Possamai, S., Daguin, A., Servent, D., et al. (2014). Neonicotinoid binding, toxicity and expression of nicotinic acetylcholine receptor subunits in the aphid Acyrthosiphon pisum. PLoS ONE 9:e96669.

Tamura, K., Stecher, G., Peterson, D., Filipski, A., and Kumar, S. (2013). MEGA6: molecular evolutionary genetics analysis version 6.0. Mol. Biol. Evol. 30, 27252729.

Taylor-Wells, J., Hawkins, J., Colombo, C., Bermudez, I., and Jones, A. K. (2017). Cloning and functional expression of intracellular loop variants of the honey bee (Apis mellifera) RDL GABA receptor. Neurotoxicology 60, 207-213.

Thany, S. H., Courjaret, R., and Lapied, B. (2008). Effect of calcium on nicotineinduced current expressed by an atypical alpha-bungarotoxin-insensitive nAChR2. Neurosci. Lett. 438, 317-321.

Thany, S. H., Crozatier, M., Raymond-Delpech, V., Gauthier, M., and Lenaers, G. (2005). Apisalpha2, Apisalpha7-1 and Apisalpha7-2: three new neuronal nicotinic acetylcholine receptor alpha-subunits in the honeybee brain. Gene 344, 125-132.

Thany, S. H., and Gauthier, M. (2005). Nicotine injected into the antennal lobes induces a rapid modulation of sucrose threshold and improves short-term memory in the honeybee Apis mellifera. Brain Res. 1039, 216-219.

Thany, S. H., Lenaers, G., Crozatier, M., Armengaud, C., and Gauthier, M. (2003). Identification and localization of the nicotinic acetylcholine receptor alpha3 mRNA in the brain of the honeybee, Apis mellifera. Insect Mol. Biol. 12, 255-262.

Thany, S. H., Lenaers, G., Raymond-Delpech, V., Sattelle, D. B., and Lapied, B. (2007). Exploring the pharmacological properties of insect nicotinic acetylcholine receptors. Trends Pharmacol. Sci. 28, 14-22.

Thompson, J. D., Higgins, D. G., and Gibson, T. J. (1994). CLUSTAL W: improving the sensitivity of progressive multiple sequence alignment through sequence weighting, position-specific gap penalties and weight matrix choice. Nucleic Acids Res. 22, 4673-4680.

Virginio, C., Giacometti, A., Aldegheri, L., Rimland, J. M., and Terstappen, G. C. (2002). Pharmacological properties of rat alpha 7 nicotinic receptors expressed in native and recombinant cell systems. Eur. J. Pharmacol. 445, $153-161$.

Wu, S., Zuo, K., Kang, Z., Yang, Y., Oakeshott, J. G., and Wu, Y. (2015). A point mutation in the acetylcholinesterase-1 gene is associated with chlorpyrifos resistance in the plant bug Apolygus lucorum. Insect. Biochem. Mol. Biol. 65, 75-82.

Yao, X., Song, F., Zhang, Y., Shao, Y., Li, J., and Liu, Z. (2009). Nicotinic acetylcholine receptor betal subunit from the brown planthopper, Nilaparvata lugens: a-to-I RNA editing and its possible roles in neonicotinoid sensitivity. Insect. Biochem. Mol. Biol. 39, 348-354.

Zhao, L., Kuo, Y. P., George, A. A., Peng, J. H., Purandare, M. S., Schroeder, K. M., et al. (2003). Functional properties of homomeric, human alpha 7-nicotinic acetylcholine receptors heterologously expressed in the SH-EP1 human epithelial cell line. J. Pharmacol. Exp. Ther. 305, 1132-1141.

Conflict of Interest: The authors declare that the research was conducted in the absence of any commercial or financial relationships that could be construed as a potential conflict of interest.

Copyright (c) 2020 Cartereau, Taillebois, Selvam, Martin, Graton, Le Questel and Thany. This is an open-access article distributed under the terms of the Creative Commons Attribution License (CC BY). The use, distribution or reproduction in other forums is permitted, provided the original author(s) and the copyright owner(s) are credited and that the original publication in this journal is cited, in accordance with accepted academic practice. No use, distribution or reproduction is permitted which does not comply with these terms. 